\title{
Optimal dye sensitized solar cell and photocapacitor performance with efficient electrocatalytic SWCNH assisted carbon electrode
}

\author{
Gurulakshmi Maddala ${ }^{1}$, Meenakshamma Ambapuram ${ }^{1}$, VijayaLaxmi Tankasala ${ }^{2}$, \\ Raghavender Mitty ${ }^{1, *}$ \\ ${ }^{1}$ Department of Physics, Yogi Vemana University, Kadapa-516005, India. \\ ${ }^{2}$ Department of Mathematics, N.T.R. Govt. Degree College for Women, \\ Mahabubnagar-509001, India. \\ * Corresponding author: toraghavender@rediffmail.com
}

The EDAX experiments confirmed as the constituted elements are present, its percentages are depicted below.

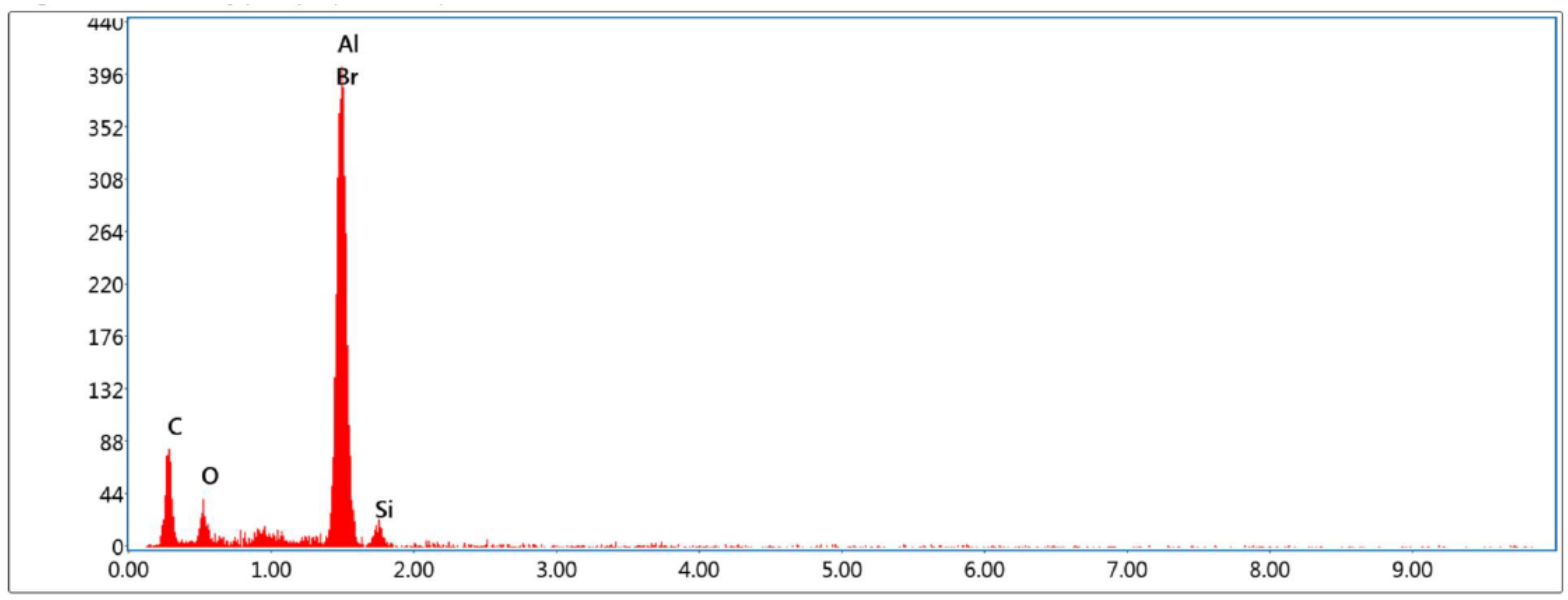

Figure S1 (a)

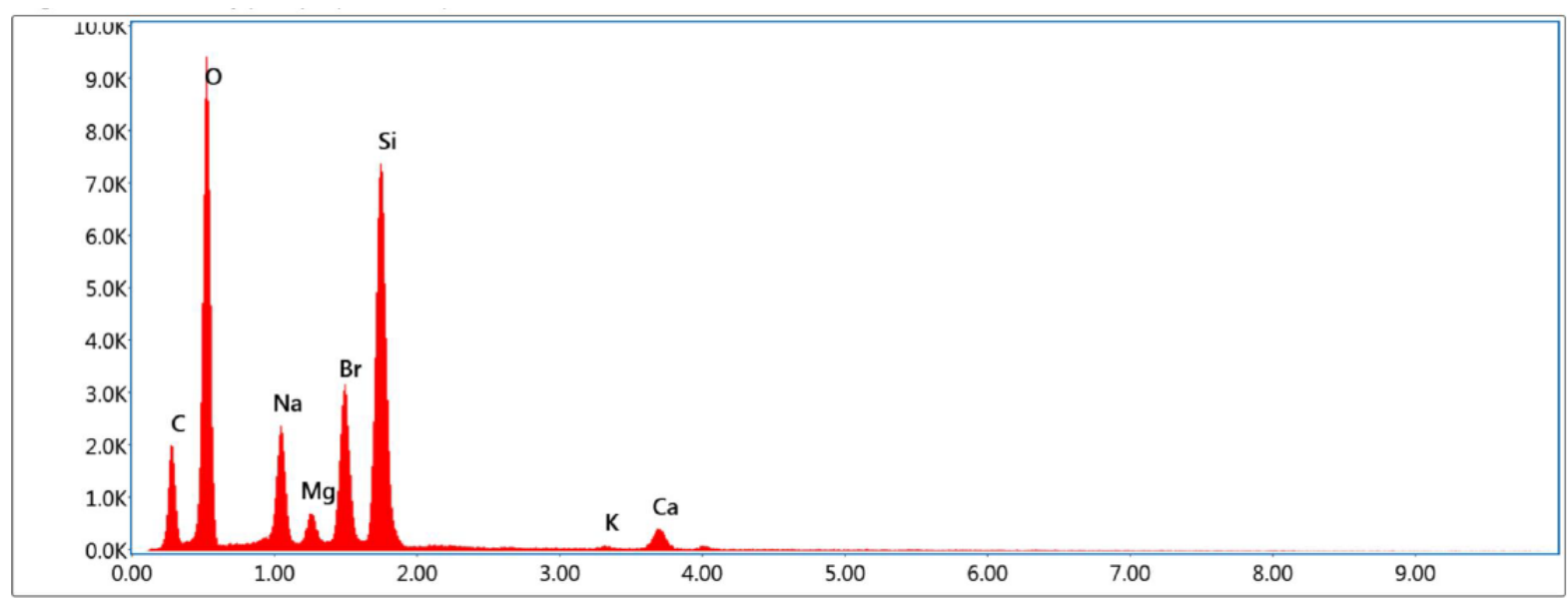

Figure S1(b)

Figure S1: (a) EDAX spectrum of Carbon (b) Carbon/SWCNH electrodes. 


\section{Supporting Information}

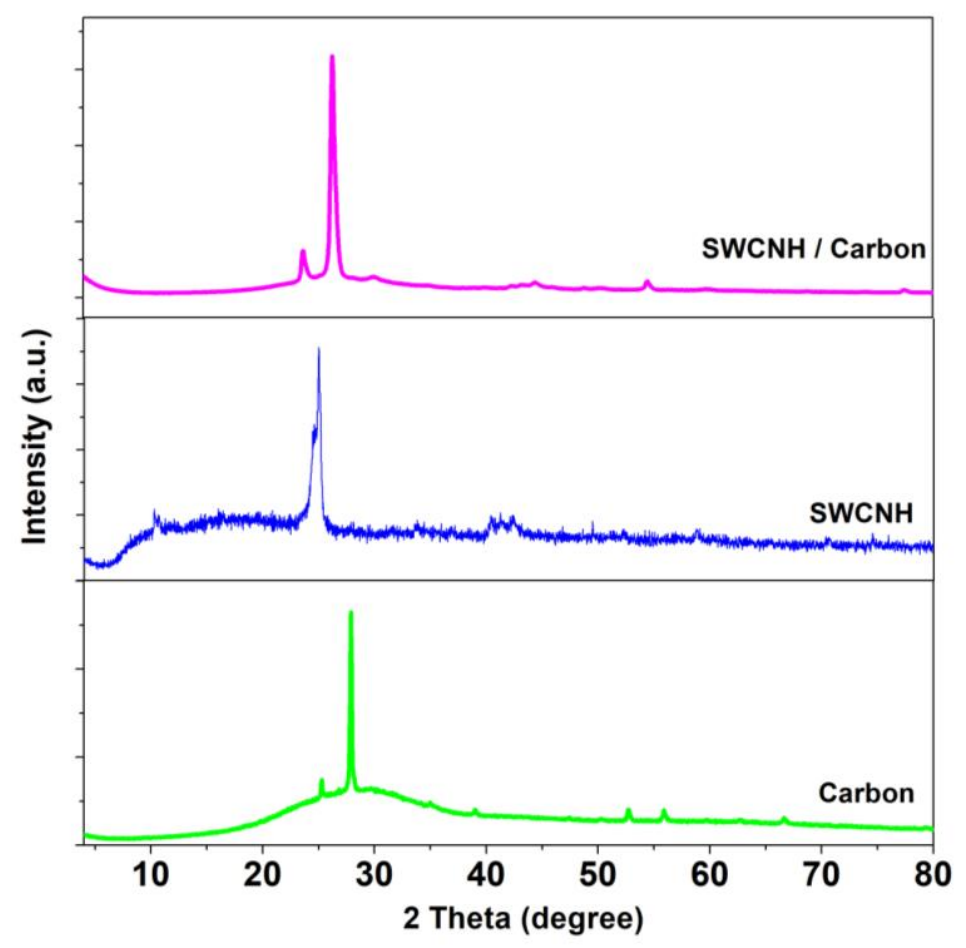

Figure S2: XRD spectra of Carbon, SWCNH and SWCNH/carbon coated electrodes.

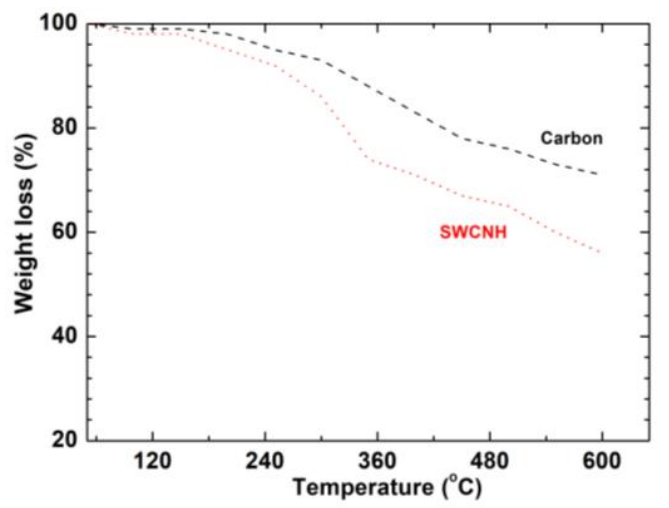

(a)

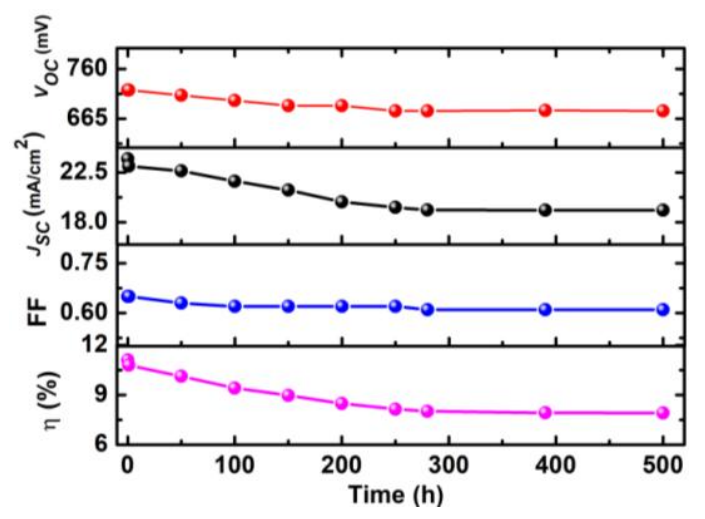

(b)

Figure S3: Stability measurement of the (a) TGA studies of SWCNH, Carbon; (b)

SWCNH/Carbon based test device with Z150 electrolyte. 